\title{
Using Negative Muons as a Probe for Depth Profiling Silver Roman Coinage
}

\author{
Bethany V. Hampshire ${ }^{1,2, *,+}$, Kevin Butcher ${ }^{3,+}{ }^{+}$Katsu Ishida ${ }^{4,+}$, George Green ${ }^{3,5,+}$, \\ Don M. Paul ${ }^{1,+}$ and Adrian D. Hillier $2, *,+$ \\ 1 Department of Physics, University of Warwick, Coventry CV4 7AL, UK; phrje@warwick.ac.uk \\ 2 ISIS Neutron and Muon Facility, STFC Rutherford Appleton Laboratory, Didcot OX11 0QX, UK \\ 3 Department of Classics and Ancient History, University of Warwick, Coventry CV4 7AL, UK; \\ K.E.T.Butcher@warwick.ac.uk (K.B.); george.green@ashmus.ox.ac.uk (G.G.) \\ 4 RIKEN Nishina Center, RIKEN, Wako, Saitama 351-0198, Japan; ishida@riken.jp \\ 5 Ashmolean Museum, Beaumont Street, Oxford OX1 2PH, UK \\ * Correspondence: B.Hampshire@warwick.ac.uk (B.V.H.); adrian.hillier@stfc.ac.uk (A.D.H.) \\ + These authors contributed equally to this work.
}

Received: 14 December 2018; Accepted: 23 January 2019; Published: 29 January 2019

\begin{abstract}
Debasement of silver Roman coins is a well-known phenomenon and understanding the quality of ancient silver coinages can provide an idea about the underlying fiscal condition of the issuing states. These coins are made from a silver-copper alloy, the surfaces of which were deliberately enhanced at the mints by a process of surface-enrichment to give them the appearance of being made of pure silver. Therefore, any surface analysis would provide a composition of the silver-copper alloy that would not be representative of the original alloy from which the coin blank was made; the result would be too high in silver. However, the bulk of the sample, the interior, should provide a composition that is true to the original alloy. Elemental analysis using negative muons has been used to provide a depth dependent compositional, completely non-destructive analysis of a silver-copper alloy denarius of the empress Julia Domna datable to 211-217 CE. The composition of the coin, beyond the surface enrichment layer, is $51 \pm 1.8 \%$ copper and $49 \pm 1.9 \%$ silver, taken at a muon depth of $402 \pm 61 \mu \mathrm{m}$. The surface enrichment layer is approximately $190 \mu \mathrm{m}$ thick.
\end{abstract}

Keywords: muon; non-destructive; elemental; analysis; silver; Roman; coin

\section{Introduction}

The quality of ancient silver coinage is often seen as a comment on the fiscal health of the issuing states. This is nowhere more apparent than with Roman coinages, which witnessed heavy debasements during the first three centuries of our era. Two processes are detectable: a reduction in the fineness of the alloys; and a reduction in weight standards. The debasement of silver Roman coinage is a common phenomenon. Most silver Roman coins are made from a silver-copper alloy that undergoes surface-enrichment, making the coin appear to be pure silver. Once the blanks for the coins were cast, they were kept at red heat in order to oxidize the copper at the surface. After the oxidation process, the blanks were soaked in an organic acid which stripped the copper out of the alloy, leaving a silver-enriched layer [1]. This technique was employed on alloys with a composition as low as $80 \%$ copper, allowing such coins to leave the mint appearing to be made of pure silver. The surface-enriched layer can be up to a few hundred microns deep [2].

In this paper, we exploit recent developments at the ISIS pulsed neutron and muon source, STFC Rutherford Appleton Laboratory, UK [3]. The negative muon has the same charge and spin as an electron. However, the mass is 207 times greater than that of an electron, with a mass of 
105.7 MeV/c $\mathrm{c}^{2}$ [4]. Due to the mass, the muonic- X-ray energy is greater than that of an electronic$\mathrm{X}$-ray, in the $10^{\prime} \mathrm{s}$ of $\mathrm{keV}$ to $\mathrm{MeV}$, allowing the possibility of using muons for bulk elemental analysis of samples as the emitted $\mathrm{X}$-rays are high enough to be emitted without significant absorption. The $\mathrm{X}$-rays emitted are characteristic of the atom of which they are captured, thus it is possible to identify the elements inside a sample through the energy of the X-rays. Controlling the momentum of the incident muon, in turn controls the implantation depth of the muon. Using negative muons for elemental analysis is a non-destructive technique and has been successfully used on Japanese coins [5], Celtic glasses [6], and extra-terrestrial materials [7]. Here, we report a study using negative muons as a probe to determine the composition of silver and copper, through a depth profile, within a denarius of Julia Domna from 211-217 CE (RIC IV.1 391: BMCRE V 31) (see Figure 1), completely non-destructively.

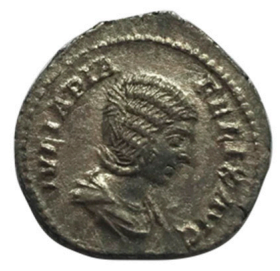

(a)

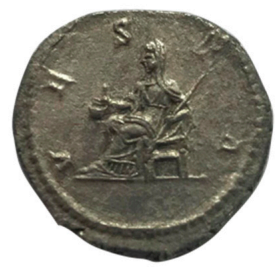

(b)

Figure 1. (a) Obverse of the Julia Domna coin analyzed: IVLIA PIA FELIX AVG, draped bust right; (b) Reverse of the same coin: VESTA, Vesta seated left. RIC IV.1 391; BMCRE V 31.

\section{Materials and Methods}

The experiment was carried out on the RIKEN-RAL beamline at ISIS [8-10] (see Figure 2a). ISIS is proton accelerator that accelerates the protons to $800 \mathrm{MeV}$ before they collide with neutron and muon targets. The ISIS facility produces both muons and neutrons. The muon target is situated before the neutron target, in Target Station 1, and is $10 \mathrm{~mm}$ thick carbon. Once protons interact with the carbon nuclei, pions are formed, these pions decay into muons [3]. These muons are then transported to the experimental area using a series of focusing and bending magnets. These magnets select a particular momentum $( \pm 4 \%)[11,12]$. The muons are then implanted into a material and give the composition of a thin slice within the sample. When the muon is captured by an atom, it displaces an electron, forming a muonic atom, and cascades down towards the nucleus through the modified energy states, emitting muonic X-rays (see Figure 3). Once the muon reaches the nucleus it either gets captured by a bound proton or decays. The muon can interact with the proton, which produces a neutron and a neutrino. This can lead to an unstable nucleus and the emission of a $\gamma$-ray [13].

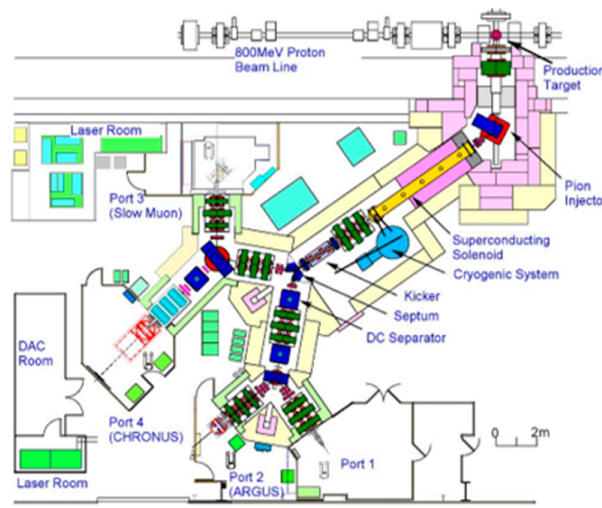

(a)

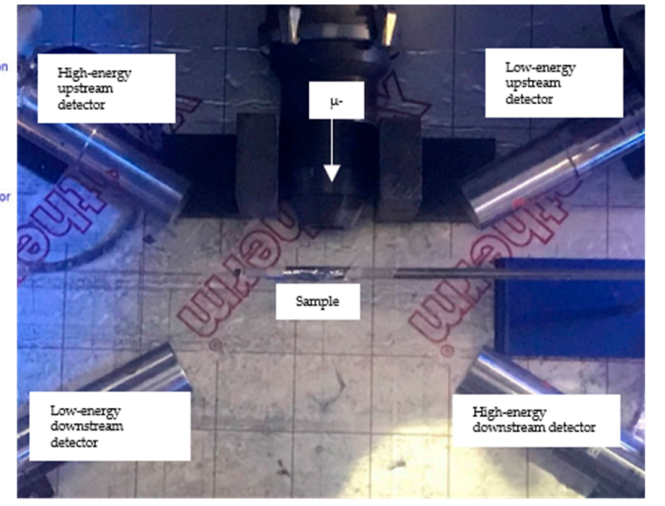

(b)

Figure 2. (a) Schematic of the Riken beamline at ISIS. The production target is made from carbon. This experiment was carried out on Port 4. (b) Experimental setup showing the orientation of the four detectors and the sample with respect to the muon beam. 


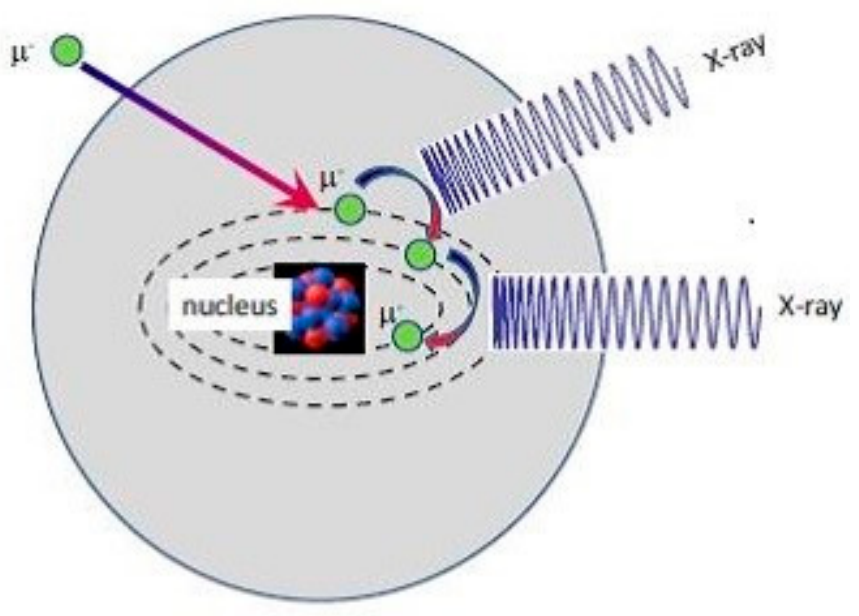

Figure 3. Schematic of muon capture by an atom.

Four ORTEC germanium detectors are used: two low-energy-high-resolution ( $3 \mathrm{keV}-1 \mathrm{MeV})$, and two high-energy-low-resolution $(0.1 \mathrm{MeV}-8 \mathrm{MeV})$. The coin was placed in an aluminum packet to support it in the beam, as a result, at the very lowest momentum aluminum peaks can be seen, these were ignored (see Figure 2b). Currently, the beam snout is constructed with lead collimators, this can lead to a signature from lead being detected. This can be in the form of lead muonic X-ray and electronic X-rays. These have been ignored in the analysis. For the analysis in this paper, the coin was treated as a binary alloy of silver and copper. Six momenta were used: $17 \mathrm{MeV} / \mathrm{c}, 18 \mathrm{MeV} / \mathrm{c}$, $19 \mathrm{MeV} / \mathrm{c}, 20 \mathrm{MeV} / \mathrm{c}, 22 \mathrm{MeV} / \mathrm{c}$, and $35 \mathrm{MeV} / \mathrm{c} .17 \mathrm{MeV} / \mathrm{c}$ and $18 \mathrm{MeV} / \mathrm{c}$ can be considered as near-surface and the aluminum packet can be seen in their spectra. SRIM [14] was used to confirm the implantation depth.

A calibration factor was used, obtained from a known standard, to apply any required weighting to the peaks to obtain a more accurate ratio of silver and copper. This is due to the efficiency of the detector decreasing as energy increases. Although the change in energy in between the peaks used in this paper is small, the calibration factor is still necessary as it also considers that peaks of different transitions were compared. The peaks used to determine composition were at 304.5 and 308.2, and 330.6 and $336.4 \mathrm{keV}$, for silver and copper respectively.

\section{Results}

Figure 4 shows typical spectra from the two upstream detectors with the muon momentum of $35 \mathrm{MeV} / \mathrm{c}$ which is an implantation depth of $402 \pm 61 \mu \mathrm{m}$. These detectors were used to reduce the effects of self-absorption for the lowest muonic X-ray energies. The spectra clearly show the presence of silver and copper, in significant abundance. It is clear that each element has multiple peaks associated with different transitions. These are labelled in Figure 4 over an energy range of 50 to $3200 \mathrm{keV}$. In order to determine the composition of the muon implantation volume the muonic $X$-rays in the 300 to $340 \mathrm{keV}$ energy range were used. In this range the $3 \mathrm{~d}_{5 / 2,3 / 2} \rightarrow 2 \mathrm{p}_{3 / 2}$ and $3 \mathrm{~d}_{3 / 2} \rightarrow 2 \mathrm{p}_{1 / 2}$ transitions of $\mathrm{Cu}$ and the $4 \mathrm{f}_{7 / 2,5 / 2} \rightarrow 3 \mathrm{~d}_{5 / 2}$ and $4 \mathrm{f}_{5 / 2} \rightarrow 3 \mathrm{~d}_{3 / 2}$ transitions of $\mathrm{Ag}$ are observed. Figure 5 shows the momentum dependence of the of the $\mathrm{Ag}$ and $\mathrm{Cu}$ peak intensities. It can clearly be seen that the lowest momentum only Ag peaks are observed and the highest momentum both $\mathrm{Ag}$ and $\mathrm{Cu}$ peaks are clearly seen. By determining the area of each peak, by fitting the peaks (see Figure 6), the relative composition can be determined, from this the depth dependent composition has been found (See Figure 7). A composition close to that of the original alloy, can be found at $402 \pm 61 \mu \mathrm{m}$, with $51 \%$ copper and $49 \%$ silver. Using the fit, this original alloy composition is reached by around $190 \mu \mathrm{m}$. Five runs were carried out in the surface layer in the range of $1.8 \pm 5 \mu \mathrm{m}$ and $54.6 \pm 13 \mu \mathrm{m}$, with the composition of silver ranging $100 \pm 7.5 \%$ and $66 \pm 2.7 \%$, respectively. 

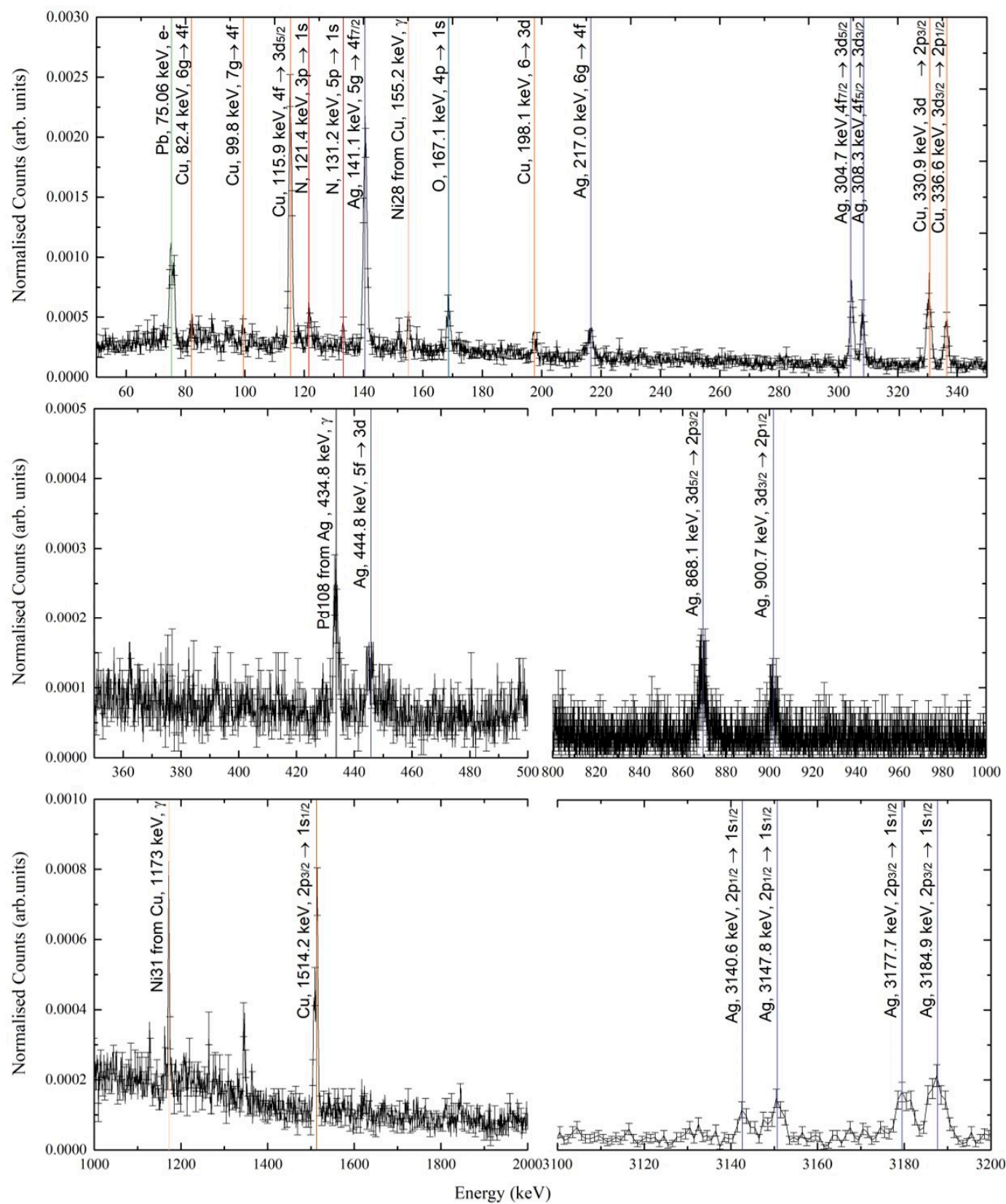

Figure 4. A typical spectrum obtained, of the Julia Domna denarius coin, in the full energy range, for both of the upstream detectors, in the energy range of 50-3300 keV. The Ni $\gamma$-peaks are due to the muon being captured by the nucleus of the $\mathrm{Cu}$ atoms and interacting with a $\mathrm{Cu}$ nucleus proton. Similarly, the Pd $\gamma$-peaks are due to the muon being captured by the Ag nucleus and interacting with a Ag nucleus proton. The peaks were identified using data from references [15-17]. 


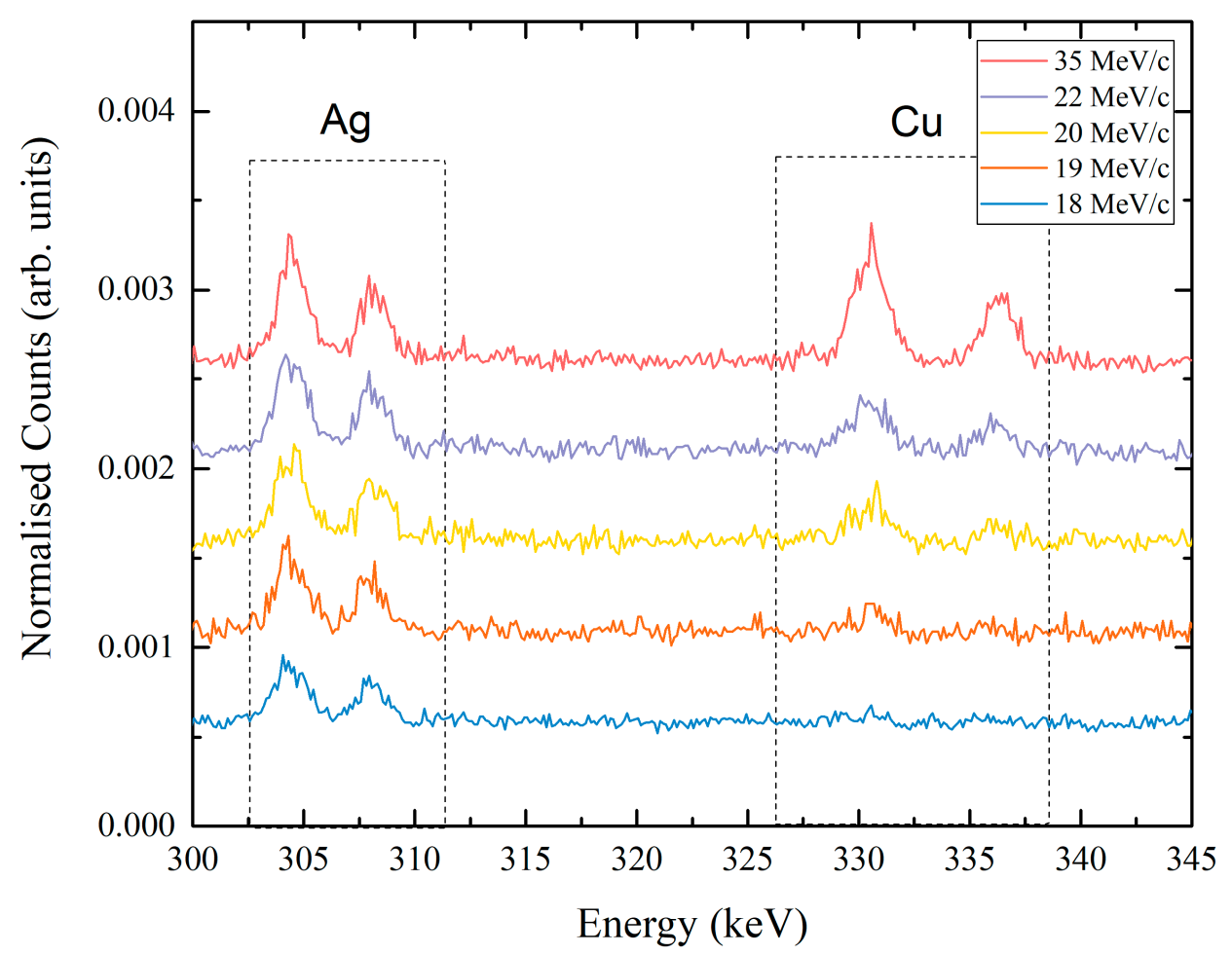

Figure 5. Silver and copper peaks in the $\mathrm{X}$-ray energy range $300-345 \mathrm{keV}$ at the muon momenta: $18 \mathrm{MeV} / \mathrm{c}, 19 \mathrm{MeV} / \mathrm{c}, 20 \mathrm{MeV} / \mathrm{c}, 22 \mathrm{MeV} / \mathrm{c}$, and $35 \mathrm{MeV} / \mathrm{c}$.

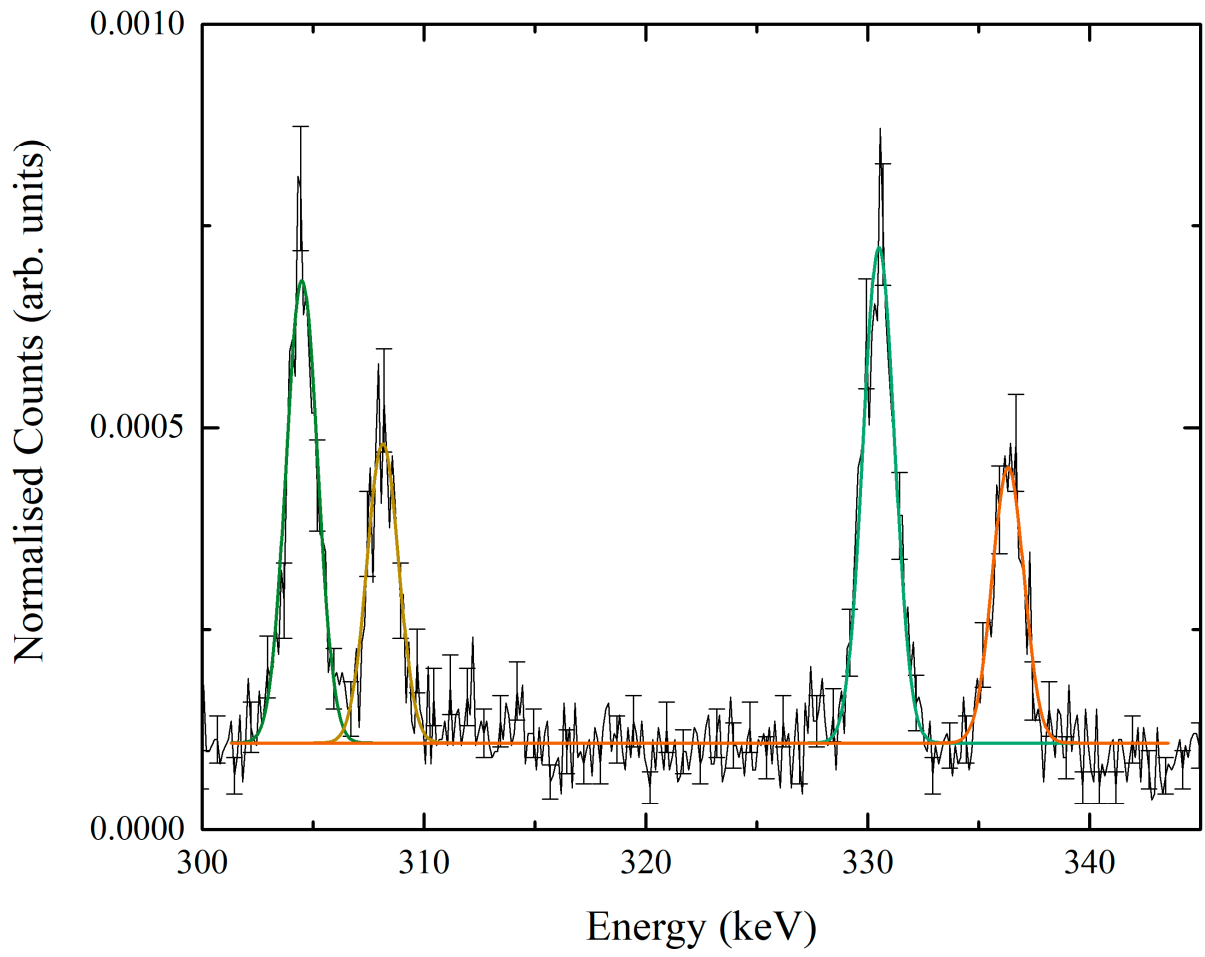

Figure 6. Silver and copper peaks in the X-ray energy range of 300-345 keV at the muon momentum of $35 \mathrm{MeV} / \mathrm{c}$ with the peaks fitted with a Gauss function.

Each of the peaks used to determine the composition were fitted with a Gauss function (see Figure 6), confining the width between them. As the energy increases the width of the peak increases, as the four peaks are in a similar range, this has a minimal effect. The sum of the integral of 
the fit was used to determine the composition with the calibration factor applied to the total of silver peaks to counteract the effects of detector efficiency and probability of capture.

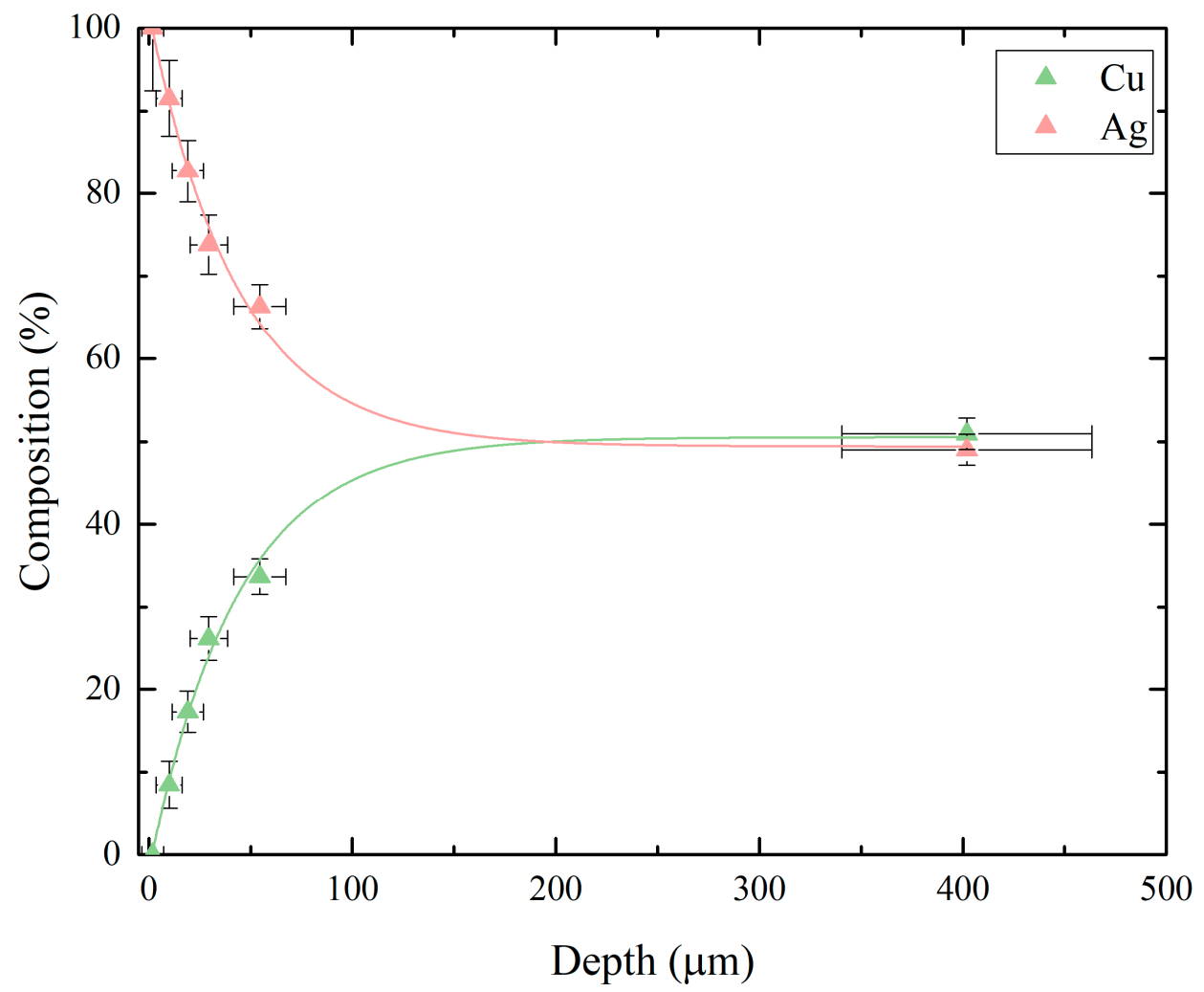

Figure 7. Composition of silver and copper, the Julia Domna denarius coin, against depth, fitted with an exponential fit. The composition reaches the true alloy, by around $190 \mu \mathrm{m}$, with a composition of $49 \%$ silver and $51 \%$ copper. Composition refers to the atomic composition.

\section{Discussion and Conclusions}

A depth profile of the composition of a silver Roman coin has been determined using negative muons, completely non-destructively. From the results: the thickness of the surface-enriched layer, the composition of the bulk, and the composition in the surface-enriched layer, can be determined using negative muons and without having to destroy the sample. The composition of the bulk of the sample is reached by around $190 \mu \mathrm{m}$, this is in accordance with the literature where the enriched surface of Roman silver-copper alloy coins is determined to be around $200 \mu \mathrm{m}$ [18]. The composition of the bulk of the sample is with $51 \pm 1.8 \%$ copper and $49 \pm 1.9 \%$ silver. The surface enriched layer has five data points in the range of $100 \pm 7.5 \%$ and $66 \pm 2.7 \%$ for the composition of silver. Elemental analysis can be used to successfully form a full depth profile of the sample by varying the momentum of the incident muon. Future work will apply this technique to study a collection of ancient silver coins with varying bulk compositions and thickness of surface-enrichment layers. The results can be used to provide more detail on the mint and the Roman Empire in the year of issue of the coins.

Author Contributions: The conceptualization was carried out by all authors, B.V.H., K.B., G.G, K.I., D.M.P., A.D.H.; Formal analysis, B.V.H., A.D.H.; Writing-original draft preparation, B.V.H. and A.D.H.; writing-review and editing, K.I., G.G., K.B.; supervision, A.D.H. and D.M.P.

Funding: This research was funded by STFC, University of Warwick and RIKEN.

Conflicts of Interest: The authors declare no conflict of interest. The funders had no role in the design of the study; in the collection, analyses, or interpretation of data; in the writing of the manuscript, or in the decision to publish the results. 


\section{References}

1. Butcher, K.; Ponting, M. The Metallurgy of Roman Silver Coinage: From the Reform of Nero to the Reform of Trajan; Cambridge University Press: Cambridge, UK, 2015; pp. 100-129.

2. Moreno-Suárez, A.I.; Ager, F.J.; Scrivano, S.; Ortega-Feliu, I.; Gómez-Tubío, B.; Respaldiza, M.A. First attempt to obtain the bulk composition of ancient silver-copper coins by using XRF and GRT. Nucl. Instrum. Methods Phys. Res. Sect. B Beam Interact. Mater. Atoms 2015, 358, 93-97. Available online: https:/ /www.sciencedirect. com/science/article/pii/S0168583X15005339?via\%3Dihub (accessed on 14 December 2018). [CrossRef]

3. Hillier, A.D.; Paul, D.M.; Ishida, K. Probing beneath the surface without a scratch-Bulk non-destructive elemental analysis using negative muons. Microchem. J. 2016, 125, 203-207. Available online: https: / / www.sciencedirect.com/science/article/pii/S0026265X1500301X?via\%3Dihub (accessed on 14 December 2018). [CrossRef]

4. Ninomiya, K.; Kubo, M.K.; Nagatomo, T.; Higemoto, W.; Ito, T.U.; Kawamura, N.; Strasser, P.; Shimomura, K.; Miyake, Y.; Suzuki, T.; et al. Nondestructive Elemental Depth-Profiling Analysis by Muonic X-ray Measurement. Anal. Chem. 2015, 87, 4597-4600. Available online: https://pubs.acs.org/doi/10.1021/ acs.analchem.5b01169 (accessed on 14 December 2018). [CrossRef] [PubMed]

5. Ninomiya, K.; Nagatomo, T.; Kubo, K.M.; Strasser, P.; Kawamura, N.; Shimomura, K.; Miyake, Y.; Saito, T.; Higemoto, W. Development of elemental analysis by muonic X-ray measurement in J-PARC. J. Phys. Conf. Ser. 2010, 225, 012040. Available online: iopscience.iop.org/article/10.1088/1742-6596/225/1/012040/meta (accessed on 14 December 2018). [CrossRef]

6. Daniel, H.; Hartmann, F.J.; Köhler, E.; Beitat, U.; Riederer, J. Application of Muonic X-Rays in Archaeology. Archaeometry 1987, 29, 110-119. Available online: https:// onlinelibrary.wiley.com/doi/abs/10.1111/j.14754754.1987.tb00402.x (accessed on 14 December 2018). [CrossRef]

7. Terada, K.; Ninomiya, K.; Osawa, T.; Tachibana, S.; Miyake, Y.; Kubo, M.K.; Kawamura, N.; Higemoto, W.; Tsuchiyama, A.; Ebihara, M.; et al. A new X-ray fluorescence spectroscopy for extraterrestrial materials using a muon beam. Sci. Rep. 2015, 4, 5072. Available online: https:/ /www.nature.com/articles/srep05072 (accessed on 14 December 2018). [CrossRef] [PubMed]

8. Nagamine, K.; Matsuzaki, T.; Ishida, K.; Watanabe, I.; Kadono, R.; Eaton, G.H.; Jones, H.J.; Thomas, G.; Williams, W.G. Construction of Riken-ral muon facility at ISIS and advanced $\mu$ SR. Hyperfine Interact. 1994, 87, 1091-1098. Available online: https:/ /rd.springer.com/article/10.1007\%2FBF02068509 (accessed on 14 December 2018). [CrossRef]

9. King, P.J.C.; Cottrell, S.P.; Cox, S.F.J.; Eaton, G.H.; Hillier, A.D.; Lord, J.S.; Pratt, F.L.; Lancaster, T.; Blundell, S.J. New science with pulsed muons-Development ideas at ISIS. Phys. B Condens. Matter. 2003, 326, 260-264. Available online: https://www.sciencedirect.com/science/article/pii/S0921452602016228?via\%3Dihub (accessed on 14 December 2018). [CrossRef]

10. Hillier, A.; Howgego, C.; Pollard, M.; Paul, D.; Wilson, A.; Ishida, K.; Hampshire, B.; Green, G. Using Negative Muons as a Non-Destructive Probe of Material Composition; STFC ISIS Facility: Didcot, UK, 2018. [CrossRef]

11. Matsuzaki, T.; Ishida, K.; Nagamine, K.; Watanabe, I.; Eaton, G.H.; Williams, W.G. The RIKEN-RAL pulsed Muon Facility. Nucl. Instrum. Methods Phys. Res. Sect. A Accel Spectrom. Detect. Assoc. Equip. 2001, 465, 365-383. Available online: http:/ /linkinghub.elsevier.com/retrieve/pii/S0168900201006945 (accessed on 14 January 2018). [CrossRef]

12. Hillier, A.D.; Lord, J.S.; Ishida, K.; Rogers, C. Muons at ISIS. Philos. Trans. R. Soc A Math. Phys. Eng. Sci. 2019, 377, 1-7. Available online: http:/ / www.royalsocietypublishing.org/doi/10.1098/rsta.2018.0064 (accessed on 14 January 2018). [CrossRef] [PubMed]

13. Moncada, F.; Cruz, D.; Reyes, A. Muonic alchemy: Transmuting elements with the inclusion of negative muons. Chem. Phys. Lett. 2012, 539-540, 209-213. Available online: https:/ /www.sciencedirect.com/science/ article/pii/S0009261412005829?via\%3Dihub (accessed on 14 January 2018). [CrossRef]

14. Ziegler, J.F.; Ziegler, M.D.; Biersack, J.P. SRIM-The stopping and range of ions in matter. Nucl. Instrum. Methods Phys. Res. Sect. B Beam Interact. Mater. Atoms 2010, 268, 1818-1823. Available online: https: / / www.sciencedirect. com/science/article/pii/S0168583X10001862?via\%3Dihub (accessed on 14 December 2018). [CrossRef] 
15. Engfer, R.; Schneuwly, H.; Vuilleumier, J.L.; Walter, H.K.; Zehnder, A. Charge-distribution parameters, isotope shifts, isomer shifts, and magnetic hyperfine constants from muonic atoms. Atom. Data Nuclear Data Tables 1974, 14, 509-597. Available online: https://www.sciencedirect.com/science/article/pii/ S0092640X74800033?via\%3Dihub (accessed on 14 January 2018). [CrossRef]

16. Zinatulina, D.; Briançon, C.; Brudanin, V.; Egorov, V.; Perevoshchikov, L.; Shirchenko, M.; Yutlandov, I.; Petitjean, C. Electronic catalogue of muonic X-rays. EPJ Web Conf. 2018, $177 . \quad$ Available online: https: / / www.epj-conferences.org/articles / epjconf/abs/2018/12/epjconf_ayss2018_03006/epjconf_ ayss2018_03006.html (accessed on 14 January 2018). [CrossRef]

17. Livechart-Table of Nuclides-Nuclear Structure and Decay Data. Available online: https://www-nds.iaea. org/relnsd/vcharthtml/VChartHTML.html (accessed on 14 January 2018).

18. Ortega-Feliu, I.; Moreno-Suárez, A.I.; Gómez-Tubío, B.; Ager, F.J.; Respaldiza, M.A.; García-Dils, S.; Rodríguez-Gutiérrez, O. A comparative study of PIXE and XRF corrected by Gamma-Ray Transmission for the non-destructive characterization of a gilded roman railing. Nucl. Instrum. Methods Phys. Res. Sect. B Beam Interact. Mater. Atoms 2010, 268, 1920-1923. Available online: https:/ /www.sciencedirect.com/science/ article/pii/S0168583X10001977?via\%3Dihub (accessed on 14 December 2018). [CrossRef]

(C) 2019 by the authors. Licensee MDPI, Basel, Switzerland. This article is an open access article distributed under the terms and conditions of the Creative Commons Attribution (CC BY) license (http:/ / creativecommons.org/licenses/by/4.0/). 